\title{
Transanal total mesorectal excision for rectal cancer: state of the art
}

\author{
Michele De Rosa ${ }^{1}$, Greg Wynn ${ }^{2}$, Fabio Rondelli ${ }^{3}$, Graziano Ceccarelli ${ }^{1}$ \\ 'Department of General Surgery, "San Giovanni Battista Hospital", Foligno 06034, Italy. \\ ${ }^{2}$ Department of General and Colorectal Surgery, East Suffolk and North Essex Foundation NHS Trust, Colchester CO45JL, \\ United Kingdom. \\ ${ }^{3}$ Department of Surgical and Biomedical Sciences, University of Perugia, Perugia 06100, Italy.
}

Correspondence to: Dr. Michele De Rosa, Department of General Surgery, "San Giovanni Battista" Hospital, Via M. Arcamone, 06034 Foligno (PG), Italy. E-mail: michele.derosa@nhs.net

\begin{abstract}
How to cite this article: De Rosa M, Wynn G, Rondelli F, Ceccarelli G. Transanal total mesorectal excision for rectal cancer: state of the art. Mini-invasive Surg 2020;4:34. http://dx.doi.org/10.20517/2574-1225.2019.53
\end{abstract}

Received: 3 Dec 2019 First Decision: 3 Feb 2020 Revised: 17 Apr 2020 Accepted: 29 Apr 2020 Published: 18 Jun 2020

Science Editor: Giulio Belli Copy Editor: Jing-Wen Zhang Production Editor: Tian Zhang

\begin{abstract}
Total mesorectal excision remains the gold standard for surgical treatment for rectal cancer to achieve excellent oncological outcomes. The transanal approach to the mesorectum was introduced to complement conventional surgery so that technical difficulties related to the distal rectal dissection could be overcome. Since its introduction, interest in transanal mesorectal excision has been growing and it appears that the benefits are maximal in patients with mid-low rectal cancer where anatomical and pathological factors present the greatest challenges. Current evidence demonstrates this approach is safe and feasible, with an acceptable morbidity profile, but with specific complications related to the technique. Oncological and functional data seem comparable to the conventional approaches, but most of the results come from small studies with short-term endpoints. Robotics, when available, might potentially overcome the difficulty of distal rectal dissection with a shorter learning curve compared to the transanal approach, but with higher costs. The aim of this review is to critically evaluate the available literature concerning transanal total mesorectal excision so that we can better define its role in the management of rectal cancer.
\end{abstract}

Keywords: Rectal cancer, total mesorectal excision, transanal total mesorectal excision, transanal surgery, laparoscopy

\section{INTRODUCTION}

Total mesorectal excision (TME) remains the gold standard approach to the surgical treatment of rectal cancer $^{[1]}$. The application of this key technical principle has represented a revolution in rectal cancer 
surgery, demonstrating how the integrity of the mesorectal envelope is paramount in achieving excellent oncological outcomes in terms of local recurrence ${ }^{[2]}$. Minimally invasive techniques have shown major benefits in the treatment of colon cancer, but rectal surgery is technically more demanding and the associated steep learning curve has made the laparoscopic approach less appealing.

Nevertheless, surgical techniques are constantly evolving and searching for less invasive approaches, particularly pursuing the principles of natural orifice transluminal endoscopic surgery (NOTES) represents an exciting goal. A further reduction in postoperative pain, less wound infections and hernias, better cosmetic results and a shorter time off work are the key advantages of these super-minimally invasive approaches $^{[3,4]}$.

It is suggested that bulky colorectal specimens can be effectively excised transanally ${ }^{[5]}$ and several experimental studies have demonstrated the safety and feasibility of rectosigmoid transanal resection in animal and cadaveric models ${ }^{[6,7]}$.

Pure NOTES still requires significant improvement in instruments and technology to make the transition to the clinical arena and remains largely an experimental approach, while hybrid procedures such as natural orifice specimen extraction (NOSE) techniques combined with laparoscopy can reduce the impact of surgery further ${ }^{[5,7,8]}$.

As a result of these experiences, the first transanal rectal resection with a hybrid approach was described by Sylla et al. ${ }^{[7]}$ in a 76 -year-old lady with a rectal cancer located at $8 \mathrm{~cm}$ from anal verge.

This first report, describing transanal TME (TaTME), aroused great interest because it demonstrated the feasibility of a hybrid NOTES procedure that could be applied to challenging real-life situations, such as the difficult TME for mid and distal rectal cancer.

Indeed, even in the hands of experts, rectal cancer surgery in obese, male patients with bulky, distal tumors can be extremely difficult, where the ballooning of rectum into the sacral concavity creates a sharp angle with the anal canal ${ }^{[9]}$. In these cases, difficulty in staying in the correct dissection plane can easily result in an incomplete specimen with possible inadequate circumferential resection margin $(\mathrm{CRM})^{[10]}$.

Despite the standardization of technique for TME, several studies have demonstrated that the quality of the final specimen is important in predicting cancer-related outcomes ${ }^{[11,12]}$. Obese patients with low, anteriorlylocated tumors, those treated with neo-adjuvant chemoradiotherapy, or those with a narrow pelvis are at particular risk of incomplete mesorectal excision ${ }^{[13-15]}$.

Laparoscopy offers the advantage of improved visualization of deep pelvic structures, but the limitations imposed by long and straight instruments, particularly applying traction and counter-traction maneuvers in a narrow space, remain significant challenges. In addition, laparoscopic stapling technology has proved rather inadequate and difficult to use low in the pelvis, increasing the risk of poor outcomes ${ }^{[16,17]}$.

TaTME was conceived and developed with the aim of overcoming these specific limitations, particularly in mid and low cancers. The closer, more detailed view of the pelvic structures makes the dissections from below more accurate and effective, leading to a better specimen. Inserting the purse-string below the tumor allows the surgeon to accurately control the distal resection margin (DRM). In the case of anterior tumors, with a high risk of an involved circumferential margin, the transanal approach can facilitate the dissection of Denonvilliers fascia, thus minimizing the risk of injuries to prostate, seminal vesicles, and the nerves of the inferior hypogastric plexus and nervi erigentes. 
Because of these potential advantages, TaTME has gained wide interest in the colorectal community and represents an opportunity to improve patient outcomes; however, it remains a technically challenging operation and further research is required to prove its oncological efficacy when more widely adopted.

\section{DEVICE AND TECHNIQUE}

In 1983, Prof. Gerard Buess conceived transanal endoscopic microsurgey (TEM) and, in cooperation with Richard Wolf, created and developed the platform for endoscopic rectal surgery, with the aim to treat benign lesions of the upper and middle rectum not previously reached with conventional transanal approaches ${ }^{[18,19]}$.

Based on this model, the Transanal Endoscopic Operation (TEO; Karl Storz, Tuttlingen, Germany) was developed, which provides a rigid operative rectoscope, compatible with many standard laparoscopic instruments without the need for a dedicated platform.

In 2009, in Orlando, Florida, Atallah and colleagues introduced the concept of transanal minimally invasive surgery (TAMIS). This was inspired by devices already created for single-site surgery in the abdomen but were adapted for transanal access. This essentially created a flexible, transanal multiport device that could be used with a conventional laparoscope and laparoscopic instruments ${ }^{[20]}$.

To date, two transanal platforms, GelPoint Path (Applied Medical, Rancho Santa Margarita, Ca) and SILS Port (Covidien, Mansfield, Ma), have gained FDA approval for TAMIS. Clinical studies published thus far demonstrate that both these and rigid platforms such as TEM/TEO can be used for TaTME, but the review by Araujo et al. ${ }^{[21]}$ shows that only the $24.7 \%(37 / 150)$ of the preliminary TaTME cases reported were performed with a platform TEM/TEO.

TAMIS ports have now become the preferred option for surgeons dedicated to TaTME because, compared to rigid platforms, the soft, flexible port offers more versatile access to the whole circumference of the rectal lumen without multiple position changes during surgery, the equipment is quicker and easier to set up, and there may also be economic advantages ${ }^{[22,23]}$.

With improving experience and the dissemination of this approach through research and training, many different technical modifications have been introduced, although the cardinal principles of this procedure remain the same: to provide a complete mobilization of the mesorectum from the pelvic floor upwards according to the eight steps described by Whiteford and colleagues in $2007^{[24]}$.

TaTME can be performed either with two different surgical teams working simultaneously with abdominal and transanal dissection or with a two-step approach, using the same surgical team for both operative phases in sequence.

Abdominal phase: the abdominal phase is performed according to the standard approach and preference of the operating surgeon. It should be noted that either a planned open approach or a laparoscopic conversion does not preclude a transanal approach to the pelvis. If a sequential approach is used (usually due to the lack of two operating teams being available), then transabdominal dissection proceeds into the pelvis along the mesorectal fascia until it becomes technically challenging and the specimen or the surrounding key pelvic structures are at risk. Even in extremely challenging cases, the peritoneum will be divided anteriorly before changing to a transanal approach as this will facilitate entry into the abdominal cavity from below. Abdominal pneumoperitoneum is deflated, the insufflator is turned off, and the ports are closed prior to the legs being positioned for the transanal phase. 
Transanal phase: the transanal phase commences with a digital rectal examination to ensure the rectum is empty and that the clinical findings correlate with the MRI scan. The placement of a self-fixing anal retractor (Lone Star CooperSurgical, Trumbull, CT, USA) may be useful to better expose the anal canal, particularly in male patients with a long anal canal. Insertion of the transanal platform should reveal distal rectal mucosa through the anal channel. Fixation of the TAMIS port to the anal margin, positioning of the ports in the gel-cap with attachment, and gentle insufflation will facilitate clear views and safe operating. Initial laparoscopic inspection will allow assessment of the height of the tumor from anal verge in order to plan the positioning of the purse-string and the rectotomy.

A purse-string suture is placed at least $10 \mathrm{~mm}$ distal to the tumor to seal the rectal lumen, and then rectal irrigation eliminates debris and prevents the possible implantation of free cancer cells.

Carbon dioxide is insufflated into the distal rectal lumen to obtain a stable pneumorectum with a pressure of $10-20 \mathrm{mmHg}$ and the rectal mucosa is marked circumferentially with monopolar hook. A full thickness rectotomy is started, usually posteriorly where the plane between presacral fascia and mesorectum is more easily identified, but slightly laterally where the ano-coccygeal ligament is less easily encountered.

The rectal transection is performed by opening the different layers of the rectal wall until the mesorectal plane is identified. Once the whole circumference of the distal rectal wall has been divided, the rectal specimen will retract upwards slightly, revealing the posterior mesorectal fascia. At this stage, the closed purse-string can be reinforced with a second $\mathrm{V}-\mathrm{Loc}^{\mathrm{TM}}$ suture (Covidien, Mansfield, Ma) to reduce the risk of intraluminal leakage during the pelvic dissection. The posterior plane is developed first, anterior to the pre-sacral fascia and along the angel hair of the mesorectal fascia which is kept intact. The anterior plane is approached afterward, keeping the dissection in front or behind Denonvillier's fascia according to the rectal cancer position. The lateral dissection can then proceed, using the areas of correct dissection from the front and back to guide the dissection; this will minimize the risk of injuries to the neurovascular structures laterally and antero-laterally. Mesorectal dissection should proceed in a cylindrical fashion avoiding distortion of the specimen. Entry into the abdominal compartment should be delayed as late as possible, as accurate mesorectal dissection is impaired once a communication is established between the two cavities. When the dissection is complete, a careful assessment is made of whether the specimen can be safely extracted transanally or not, considering the size of both the specimen but also the stage of the cancer. The length of the remaining distal rectal cuff will determine whether a hand-sewn anastomosis will be required or whether there is adequate tissue for a distal purse-string to be inserted in preparation for a stapled anastomosis. Distal purse-strings can be inserted laparoscopically or as an open procedure with the TAMIS port still in-situ but drawn distally to stent the anorectal lumen or with the TAMIS port removed and the Lone Star retractor giving access. Various methods of stapled anastomosis techniques have been described $^{[25]}$.

Techniques to assess the vascular supply to the anastomosis have been described ${ }^{[26]}$, but one of the benefits of TaTME is direct inspection and palpation of the whole circumference of the anastomosis prior to the end of the operation. This may allow selective defunctioning stomas to be performed according to individual patient risk factors.

\section{INDICATIONS}

Ideal candidates for TaTME are patients with mid or low rectal cancer (within $10 \mathrm{~cm}$ from the anal verge), especially in male patients (because of the narrow pelvis or prostate hypertrophy/previous prostate surgery), obesity, bulky tumors, or after neoadjuvant radiotherapy, and, for these reasons, this approach may have the most to offer these patients. The San Gallen Consensus concurs that TaTME may be technically easier compared to abdominal techniques in this group of patients ${ }^{[27]}$. 
Current practice suggests that selection of patients for TaTME includes a wider group of patients, particularly with regard with tumor location, as we can observe with the experience of Lacy or in the International Registry where tumors were proximally located in $20.7 \%$ and $38 \%$ of patients, respectively ${ }^{[28,29]}$, however this remains primarily a technique for those requiring TME.

Appropriate patient selection is of paramount importance, especially during the early learning curve and it is wise not to select very difficult cases before competence is reached. In this respect, expanding the indications for TaTME to include those patients who could easily be done laparoscopically may be required for training purposes.

\section{PERIOPERATIVE RESULTS}

Feasibility and safety of perioperative outcomes of TaTME have been extensively reported as well as limitations and shortcomings that need to be addressed.

Reduced estimated blood loss, shorter hospital stay, and lower readmission rates were recently reported in a meta-analysis of 17 studies $^{[30]}$.

Compared to laparoscopic TME, a lower rate of conversion to open surgery has been observed, ranging between $0 \%$ and $9.1 \%^{[22,31,32]}$. This correlated to the level of experience, as highlighted by Dejien and colleagues who compared low-volume centers performing TaTME ( $<30$ cases) to high-volume centers $(>30$ cases) and reported conversion rates of $4.3 \%$ and $2.7 \%$, respectively ${ }^{[33]}$.

Conversions during TME surgery are usually due to technical difficulties related to high body mass index (BMI) and the narrow male pelvis. Ma et al. ${ }^{[32]}$ showed that this accounted for $25 \%$ of conversions in TaTME patients vs. $47 \%$ in those undergoing laparoscopic TME. In most reported series, the occurrence of intraoperative complications provoke conversion, with tumor or patient features not directly affecting the operation outcome.

TaTME has also been shown to have a significantly shorter operation time, compared to laparoscopy ${ }^{[34]}$, and this is even more pronounced if the operation is performed with a simultaneous two-team approach ${ }^{[35]}$.

Concerning morbidity, several retrospective series or cohort studies reported on safety of TaTME, showing postoperative complication rates comparable with conventional laparoscopic or open TME data ${ }^{[36]}$.

The international TaTME registry including 720 patients reported an overall morbidity of $32.5 \%{ }^{[29]}$, in line with several other monocentric series on TaTME ${ }^{[2,37]}$.

In a recent systematic review, TaTME and laparoscopic TME showed similar rates of intraoperative complications, although a lower rate of postoperative morbidity was reported in the transanal group ${ }^{[32]}$.

Several publications report a low incidence of anastomotic leak rate following TaTME, which in the largest meta-analyses available ranges between $5.7 \%$ and $6.1 \%^{[33,38]}$ and is similar to the results reported after conventional TME ${ }^{[39]}$.

Recently updated data from the multi-institutional International TaTME registry on 1594 patients over 30 months show an overall 30 -day anastomotic leak rate of $7.8 \%^{[40]}$, not too far from the rate of $10 \%$ reported by Ma et al..$^{[32]}$ in their systematic review. 
Finally, the potential for major bacterial contamination as a consequence of the rectal transection, as shown by Velthuis with $39 \%$ of positivity of pelvic culture, suggests the risk for higher rates of pelvic sepsis, but this concern was not confirmed by subsequent studies ${ }^{[41]}$.

Indeed, the literature available reports an average rate of pelvic abscess of $2 \%-3 \%{ }^{[29,42]}$ and more up to date review data confirm an overall incidence of $2.2 \%{ }^{[33]}$.

Despite these encouraging results, TaTME has some very specific complications. Rouanet reported urethral injury in $6.6 \%$ of cases; however, this was a series of 30 difficult high BMI male patients, most following radiotherapy ${ }^{[43]}$. However, urethral injury is a serious complication directly related to the transanal phase of the operation and is very uncommon during open or laparoscopic TME.

In the largest multi-institutional registry reporting on 720 patients, the occurrence of urethral injuries was $0.7 \%$ and was associated with bladder injuries, vaginal and rectal perforations, and damage to hypogastric nerves ${ }^{[29]}$.

Another matter of concern specific of this technique is the possibility by pneumo-pelvis of creating a false dissection plan, misleading the surgeon and increasing the risk of inadvertent damages of sidewall autonomic nerves and vessels laterally and of sacral venous plexus posteriorly ${ }^{[29]}$.

Finally, carbon dioxide embolism during TaTME, a rare but potentially life-threatening complication, was reported by Ratcliffe et al. ${ }^{[4]]}$ and may occur in up to $0.4 \%$ of patients, mandating conversion to open and giving rise to postoperative morbidity ${ }^{[45]}$.

\section{ONCOLOGICAL RESULTS}

TaTME was conceived to overcome some of the technical challenges in rectal cancer surgery, enabling dissection of a high quality mesorectal envelope. Soon after its introduction, several preliminary reports showed a good quality mesorectum in almost all cases, negative circumferential and distal margins, and a level of lymph node harvesting comparable with the conventional approach ${ }^{[37,46,47]}$.

These results are important since an incomplete TME represents an independent risk factor for local recurrence, regardless of the achievement of circumferential and distal negative margins ${ }^{[48]}$.

With an intact mesorectal fascia, the likelihood of local recurrence, even with involved lymph nodes, is significantly lower than with a threatened one and is around $7.5 \%{ }^{[49]}$.

Negativity of circumferential margin is another indicator of the quality of the rectal resection and its involvement is reported in $8 \%-10 \%$ of cases $^{[50]}$.

Fernández-Hevia et al. ${ }^{[22]}$ confirmed this trend by comparing TaTME with laparoscopy in a matchcontrolled study showing similar numbers of lymph nodes harvested and negative circumferential margin in all cases.

Velthuis obtained similar results demonstrating that with a transanal approach a significantly higher rate of complete mesorectal excision could be achieved, compared with laparoscopic patients ${ }^{[51]}$.

In an early meta-analysis reporting data on 510 patients, a complete TME specimen was reported in $88 \%$ of cases and near complete in $6 \%$, while CRM was positive in $5 \%$ of cases and the DRM in $0.3 \%$ of cases ${ }^{[38]}$. 
Hu et al. ${ }^{[52]}$ showed that a complete mesorectal excision rate was 1.93 higher in the TaTME compared to laparoscopic TME, with a lower positive CRM rate, while positive DRM rate did not reach statistical difference.

Recently, in 513 TaTME procedures performed in the UK, optimal pathology was observed in 295 patients $(92.8 \%)$, with an involved resection margin (R1) in 13 patients $(4.1 \%)^{[53]}$.

Can these preliminary short-term pathological advantages translate into the final target of a lower recurrence rate?

Lelong et al ${ }^{[54]}$ in a comparative series including 72 patients, with a median follow-up period of 31.9 months, demonstrated similar results following laparoscopic or TaTME (5.3\% and 5.7\% local recurrence rate, respectively), but, considering only patients with curative resections (no metastases at diagnosis), local recurrence rates were $5.7 \%$ and $0 \%$, respectively.

A two-center experience of 159 TaTMEs procedures showed the 3- and 5-year local recurrence rates were $2 \%$ and $4.0 \%$, respectively, with a median time to local recurrence of 19.2 months (range 5.9-30.0 months) ${ }^{[55]}$.

On the other hand, the Norwegian Colorectal Cancer Group expressed a warning against this technique, reporting a $9.5 \%$ rate of early local recurrence with rapid, multifocal growth in the pelvic cavity and sidewalls, and a median time to recurrence of 11 months. The observed local recurrence rate following laparoscopic TME was $3.4 \%{ }^{[56]}$.

The small sample size of the experiences published thus far underline the need for a larger multicenter RCT for TaTME to better assess the long-term oncological results compared to conventional techniques.

\section{FUNCTIONAL RESULTS}

Bowel, sexual, and urinary dysfunction is common after rectal cancer surgery and is associated with social and psychological impairment. Anorectal disturbance can be caused by sphincter damage, reduced capacity of the neo-rectum, level of anastomosis, pelvic nerve damage, and the effects of radiotherapy. Up to one third of patients experience "anterior resection syndrome", which is characterized by functional disorders such as urgency, increased bowel frequency, fragmentation, and incontinence. A similar proportion experiences genitourinary problems, including impotence and retrograde ejaculation in men and sexual dysfunction in both sexes.

The relationship between these functional complaints and the quality of life perception is difficult to establish and poorly reported in the literature. In general, major bowel and urinary alterations affect social functioning, while incontinence and fecal urgency also impact on mental health.

With acceptable perioperative and oncological results, functional outcome and quality of life measures after TaTME represent important outcomes for patients.

The transanal approach for low rectal cancer has not been shown to significantly increase bowel and urologic dysfunction, compared to conventional laparoscopy, but may be associated with better erectile function with a significantly higher rate of sexual activity ${ }^{[57,58]}$. Quality of life and functional outcomes, assessed by validated questionnaires, showed acceptable outcomes after TaTME at 6 months after surgery $^{[59]}$. 
Rubinkiewicz et al. ${ }^{[60]}$, in a comparative study concerning the occurrence and severity of low anterior resection syndrome, reported similar results between TaTME and LaTME, with a prevalence still high in both groups ( $87 \%$ and $91 \%$, respectively).

Assessment of patients after TaTME by transanal endoscopic ultrasound and physiological functional assessments concluded that TaTME has no impact on sphincter structure and evacuatory function, with about $10 \%$ of patients with major low anterior resection syndrome after 1 year ${ }^{[61]}$.

In conclusion, TaTME does not appear to increase the negative impact on functional and quality of life outcomes if compared to conventional laparoscopic transabdominal TME. Existing data concerning anorectal, urinary, and sexual function and quality of life following TaTME are still of low quality and further studies are needed in this area.

\section{ROBOTIC TaTME}

Robotic approaches can overcome several of the technical difficulties associated with traditional laparoscopic surgery and allow high-quality maneuvers to be performed in narrow spaces such as the pelvic cavity. Recent studies demonstrate similar clinical and oncological results between robotic and laparoscopic transabdominal surgical procedures ${ }^{[62]}$, but, at present, no significant benefit of robotic over laparoscopic surgery seems to be detectable, except perhaps conversion rates.

The application of robotic technology to TaTME (rTaTME) appears to be the next logical step in the evolution of minimal access surgery, allowing the benefits of improved dexterity, stability of the platform, and $3 \mathrm{D}$-vision, while adhering to the principles of NOTES.

Small rTaTME case series have been reported demonstrating feasibility. Kuo et al.$^{[63]}$ described a combined rTaTME and transabdominal single-site plus one port approach in 16 patients with low rectal lesions, showing good oncological results.

More recently, Hu et al. ${ }^{[64]}$ published a case series of 20 patients treated with r-TaTME with simultaneous laparoscopic-assisted abdominal phase performed with single-port placed at ileostomy site, demonstrating the applicability of this approach, but also highlighting some of the limitations of the Da Vinci Xi platform for transanal surgery.

The introduction of the robotic platform based on the single-port access may represent the start of a new era for robot-assisted transanal surgery, but ultimately smaller, more flexible robotic systems are required for true natural orifice procedures where scars are eliminated. If this can be combined with cost control, then a new era in surgery will be possible.

\section{CONCLUSION}

TaTME has demonstrated some tantalizing benefits for the surgeon and the patient, but remains controversial because of the lack of long-term oncological data and the technical operative challenges that make widespread dissemination difficult.

Some consider TaTME as the culmination of 30 years of progress in colorectal cancer surgery ${ }^{[65]}$. Others, while applauding the results achieved to date, introduce a note of caution in their interpretation of the available data, as the majority of the published experience originates from highly trained surgeons in highvolume centers with great heterogeneity among studies ${ }^{[66]}$. It is important that we avoid the indiscriminate adoption by inadequately trained surgeons that could undermine the progress achieved thus far ${ }^{[67]}$. 
The debate will continue as to whether this should be an operation that is used selectively for the most difficult cases - in which case, expect worse outcomes - or whether it is a panacea to improve all rectal cancer surgery and therefore outcomes more widely ${ }^{[43,46]}$.

The distal third of the rectum remains challenging even in highly experienced surgical hands ${ }^{[68]}$ and could be difficult to reach transabdominally, sometimes at the price of an unavoidable derogation to principles of oncological radicality and nerve preservation. Even Bill Heald, the master of TME, in very challenging conditions used manual dissection to get out of otherwise impossible situations ${ }^{[69]}$.

For this reason, Heald himself has embraced and supported this conceptual revolution, considering the pneumodissection and the vision from below of great help in the challenging steps of the distal dissection, mainly on the anterior plane in the male pelvis, with a consequent better identification and preservation of nerves. Excited by Lacy's message, he considered it as the future of rectal cancer surgery ${ }^{[70]}$.

With similar postoperative complications when compared to standard laparoscopic or open TME, remarkable short-term pathological and surgical results, and promising long-term oncologic outcomes, the available literature suggests that TaTME is safe and feasible in the hands of surgeons who have had proper training and been supported through the early learning curve. If this technique is to be widely adopted, then formal training programs with adequate resources will have to be available to facilitate wider adoption without the increase in complications ${ }^{[71]}$.

The multicentric randomized controlled trial COLOR III, designed to compare TaTME and Laparoscopic TME is currently underway and will produce more reliable evidence concerning the quality of this type of surgery.

If the results already demonstrated are confirmed, TaTME should be considered among the gold standard approaches to be offered to selected high-risk patients with rectal cancer.

\section{DECLARATIONS}

\section{Authors' contributions}

Substantial contributions to conception and draft of the manuscript: De Rosa M, Wynn G, Rondelli F Critical revision: Ceccarelli G, Wynn G

\section{Availability of data and materials}

Not applicable.

\section{Financial support and sponsorship}

None.

\section{Conflicts of interest}

All authors declared that there are no conflicts of interest.

\section{Ethical approval and consent to participate}

Not applicable.

\section{Consent for publication}

Not applicable.

\section{Copyright}

(c) The Author(s) 2020. 


\section{REFERENCES}

1. Heald RJ, Husband EM, Ryall RD. The mesorectum in rectal cancer surgery: the clue to pelvic recurrence? Br J Surg 1982;69:613-6.

2. Heald RJ, Ryall RD. Recurrence and survival after total mesorectal excision for rectal cancer. Lancet 1986;327:1479-82.

3. Kalloo AN, Singh VK, Jagannath SB, Niiyama H, Hill SL, et al. Flexible transgastric peritoneoscopy: a novel approach to diagnostic and therapeutic interventions in the peritoneal cavity. Gastrointest Endosc 2004;60:114-7.

4. Lehmann KS, Ritz JP, Wibmer A, Gellert K, Zornig C, et al. The German registry for natural orifice translumenal endoscopic surgery: report of the first 551 patients. Ann Surg 2010;252:263-70.

5. Lacy AM, Saavedra-Perez D, Bravo R, Adelsdorfer C, Aceituno M, et al. Minilaparoscopy-assisted natural orifice total colectomy: technical report of a minilaparoscopy-assisted transrectal resection. Surg Endosc 2012;26:2080-5.

6. Sylla P, Willingham FF, Sohn DK, Gee D, Brugge WR, et al. NOTES rectosigmoid resection using transanal endoscopic microsurgery (TEM) with transgastric endoscopic assistance: a pilot study in swine. J Gastrointest Surg 2008;12:1717-23.

7. Sylla P, Rattner DW, Delgado S, Lacy AM. NOTES transanal rectal cancer resection using transanal endoscopic microsurgery and laparoscopic assistance. Surg Endosc 2010;24:1205-10.

8. Lacy AM, Adelsdorfer C, Delgado S, Sylla P, Rattner DW. Minilaparoscopy-assisted transrectal low anterior resection (LAR): a preliminary study. Surg Endosc 2013;27:339-46.

9. Hamilton E. Ballooning of the rectum. Trans RAM Ireland 1892;10:159.

10. Bondeven P, Hagemann-Madsen RH, Laurberg S, Pedersen BG. Extent and completeness of mesorectal excision evaluated by postoperative magnetic resonance imaging. Br J Surg 2013;100:1357-67.

11. Maslekar S, Sharma A, Macdonald A, Gunn J, Monson JR, et al. Mesorectal grades predict recurrences after curative resection for rectal cancer. Dis Colon Rectum 2007;50:168-75.

12. Baik SH, Kim NK, Lee KY, Sohn SK, Cho CH, et al. Factors influencing pathologic results after total mesorectal excision for rectal cancer: analysis of consecutive 100 cases. Ann Surg Oncol 2008;15:721-8.

13. García-Granero E, Faiz O, Flor-Lorente B, García-Botello S, Esclápez P, et al. Prognostic implications of circumferential location of distal rectal cancer. Colorectal Dis 2011;13:650-7.

14. Targarona EM, Balague C, Pernas JC, Martinez C, Berindoague R, et al. Can we predict immediate outcome after laparoscopic rectal surgery? multivariate analysis of clinical, anatomic, and pathologic features after 3-dimensional reconstruction of the pelvic anatomy. Ann Surg 2008;247:642-9.

15. You JF, Tang R, Changchien CR, Chen JS, You YT, et al. Effect of body mass index on the outcome of patients with rectal cancer receiving curative anterior resection: disparity between the upper and lower rectum. Ann Surg 2009;249:783-7.

16. Brannigan AE, De Buck S, Suetens P, Penninckx F, D’Hoore A. Intracorporeal rectal stapling following laparoscopic total mesorectal excision: overcoming a challenge. Surg Endosc 2006;20:952-5.

17. Braunschmid T, Hartig N, Baumann L, Dauser B, Herbst F. Influence of multiple stapler firings used for rectal division on colorectal anastomotic leak rate. Surg Endosc 2017;31:5318-26.

18. Buess G, Kipfmüller K, Ibald R, Heintz A, Hack D, et al. Clinical results of transanal endoscopic microsurgery. Surg Endosc 1988;2:24550.

19. Buess G, Mentges B, Manncke K, Starlinger M, Becker HD. Technique and results of transanal endoscopic microsurgery in early rectal cancer. Am J Surg 1992;163:63-9.

20. Atallah S, Albert M, Larach S. Transanal minimally invasive surgery: a giant leap forward. Surg Endosc 2010;24:2200-5.

21. Araujo SE, Crawshaw B, Mendes CR, Delaney CP. Transanal total mesorectal excision: a systematic review of the experimental and clinical evidence. Tech Coloproctol 2015;19:69-82.

22. Fernández-Hevia M, Delgado S, Castells A, Tasende M, Momblan D, et al. Transanal total mesorectal excision in rectal cancer: shortterm outcomes in comparison with laparoscopic surgery Ann Surg 2015;261:221-7.

23. McLemore EC, Coker A, Jacobsen G, Talamini MA, Horgan S. eTAMIS: endoscopic visualization for transanal minimally invasive surgery. Surg Endosc 2013;27:1842-5.

24. Whiteford MH, Denk PM, Swanstrom LL. Feasibility of radical sigmoid colectomy performed as natural orifice translumenal endoscopic surgery (NOTES) using transanal endoscopic microsurgery. Surg Endosc 2007;21:1870-4.

25. Penna M, Knol JJ, Tuynman JB, Tekkis PP, Mortensen NJ, et al. Four anastomotic techniques following transanal total mesorectal excision (TaTME). Tech Coloproctol 2016;20:185-91.

26. Otero-Piñeiro AM, de Lacy FB, Van Laarhoven JJ, Martín-Perez B, Valverde S, et al. The impact of fluorescence angiography on anastomotic leak rate following transanal total mesorectal excision for rectal cancer: a comparative study. Surg Endosc 2020; Epub ahead of print. doi: 10.1007/s00464-020-07442-6.

27. Adamina M, Buchs NC, Penna M, Hompes R; St.Gallen Colorectal Consensus Expert GroupSt. Gallen consensus on safe implementation of transanal total mesorectal excision. Surg Endosc 2018;32:1091-103.

28. Lacy AM, Tasende MM, Delgado S, Fernandez-Hevia M, Jimenez M, et al. Transanal total mesorectal excision for rectal cancer: outcomes after 140 patients. J Am Coll Surg 2015;221:415-23.

29. Penna M, Hompes R, Arnold S, Wynn G, Austin R, et al. Transanal total mesorectal excision. international registry results of the first 720 cases. Ann Surg 2017;266:111-7.

30. Lei P, Ruan Y, Yang X, Fang J, Chen T. Trans-anal or trans-abdominal total mesorectal excision? A systematic review and meta-analysis of recent comparative studies on perioperative outcomes and pathological result. Int J Surg 2018;60:113-9.

31. Buchs NC, Wynn G, Austin R, Penna M, Findlay JM, et al. A two-centre experience of transanal total mesorectal excision. Colorectal Dis 
2016;18:1154-61.

32. Ma B, Gao P, Song Y, Zhang C, Zhang C, et al. Transanal total mesorectal excision (taTME) for rectal cancer: a systematic review and meta-analysis of oncological and perioperative outcomes compared with laparoscopic total mesorectal excision. BMC Cancer 2016;16:380.

33. Deijen CL, Tsai A, Koedam TW, Veltcamp Helbach M, Sietses C, et al. Clinical outcomes and case volume effect of transanal total mesorectal excision for rectal cancer: a systematic review. Tech Coloproctol 2016;20:811-24.

34. Xu W, Xu Z, Cheng H, Ying J, Cheng F, et al. Comparison of short-term clinical outcomes between transanal and laparoscopic total mesorectal excision for the treatment of mid and low rectal cancer: A meta-analysis. Eur J Surg Oncol 2016;42:1841-50.

35. Koedam TWA, Veltcamp Helbach M, van de Ven PM, Kruyt PM, van Heek NT, et al. Transanal total mesorectal excision for rectal cancer: evaluation of the learning curve. Tech Coloproctol 2018;22:279-87.

36. Guillou PJ, Quirke P, Thorpe H, Walker J, Jayne DG, et al.; MRC CLASICC trial group. Short-term endpoints of conventional versus laparoscopicassisted surgery in patients with colorectal cancer (MRC CLASICC trial): multicentre, randomised controlled trial. Lancet 2005;365:1718-26.

37. Veltcamp Helbach M, Deijen CL, Velthuis S, Bonjer HJ, Tuynman JB, et al. Transanal total mesorectal excision for rectal carcinoma: short-term outcomes and experience after 80 cases. Surg Endosc 2016;30:464-70.

38. Simillis C, Hompes R, Penna M, Rasheed S, Tekkis PP. A systematic review of transanal total mesorectal excision: is this the future of rectal cancer surgery? Colorectal Dis 2016;18:19-36.

39. Hua L, Wang C, Yao K, Zhang J, Chen J, et al. Is the incidence of postoperative anastomotic leakage different between laparoscopic and open total mesorectal excision in patients with rectal cancer? A meta-analysis based on randomized controlled trials and controlled clinical trials. J Can Res Ther 2014;10:272-5.

40. Penna M, Hompes R, Arnold S, Wynn G, Austin R, et al. Incidence and risk factors for anastomotic failure in 1594 patients treated by transanal total mesorectal excision: results from the international TaTME registry. Ann Surg 2019;269:700-11.

41. Velthuis S, Veltcamp Helbach M, Tuynman JB, Le TN, Bonjer HJ, et al. Intra-abdominal bacterial contamination in TAMIS total mesorectal excision for rectal carcinoma: a prospective study. Surg Endosc 2015;29:3319.

42. Wolthuis AM, Bislenghi G, Overstraeten ABV, D’Hoore A. Transanal total mesorectal excision: towards standardization of technique. World J Gastroenterol 2015;21:12686-95.

43. Rouanet P, Mourregot A, Azar CC, Carrere S, Gutowski M, et al. Transanal endoscopic proctectomy: an innovative procedure for difficult resection of rectal tumors in men with narrow pelvis. Dis Colon Rectum 2013;56:408-15.

44. Ratcliffe F, Hogan AM, Hompes R. CO2 embolus: an important complication of TaTME surgery. Tech Coloproctol 2017;21:61-2.

45. Dickson EA, Penna M, Cunningham C, Ratcliffe FM, Chantler J, et al. Carbon dioxide embolism associated with total mesorectal excision surgery. Dis Colon Rectum 2019;62:794-801.

46. Tuech JJ, Karoui M, Lelong B, De Chaisemartin C, Bridoux V, et al. A step toward NOTES total mesorectal excision for rectal cancer: endoscopic transanal proctectomy. Ann Surg 2015;261:228-33.

47. De Rosa M, Rondelli F, Boni M, Ermili F, Bugiantella W, et al. Transanal total mesorectal excision (TaTME): single-centre early experience in a selected population. Updates Surg 2019;71:157-63.

48. Nagtegaal ID, van de Velde CJ, van der Worp E, Kapiteijn E, Quirke P, et al. Macroscopic evaluation of rectal cancer resection specimen: clinical significance of the pathologist in quality control. J Clin Oncol 2002;20:1729-34.

49. Cecil TD, Sexton R, Moran BJ, Heald RJ. Total mesorectal excision results in low local recurrence rates in lymph node positive rectal cancer. Dis Colon Rectum 2004;47:1145-9.

50. Rullier E, Denost Q, Vendrely V, Rullier A, Laurent C. Low rectal cancer: classification and standardization of surgery. Dis Colon Rectum 2013;56:560-7.

51. Velthuis S, Nieuwenhuis DH, Ruijter TE, Cuesta MA, Bonjer HJ, et al. Transanal versus traditional laparoscopic total mesorectal excision for rectal carcinoma. Surg Endosc 2014;28:3494-9.

52. Hu D, Jin P, Hu L, Liu W, Zhang W, et al. The application of transanal total mesorectal excision for patients with middle and low rectal cancer: a systematic review and metaanalysis. Medicine (Baltimore) 2018;97:e11410.

53. Roodbeen SX, Penna M, Arnold S, Wynn G, Warusavitarne J, et al. UK TaTME Registry Collaborative. A nationwide study on the adoption and short-term outcomes of transanal total mesorectal excision in the UK. Minerva Chir 2019;74:279-88.

54. Lelong B, Meillat H, Zemmour C, Poizat F, Ewald J, et al. Short- and mid-term outcomes after endoscopic transanal or laparoscopic transabdominal total mesorectal excision for low rectal cancer: a single institutional case-control study. J Am Coll Surg 2017;224:917-25.

55. Hol JC, van Oostendorp SE, Tuynman JB, Sietses C. Long-term oncological results after transanal total mesorectal excision for rectal carcinoma. Tech Coloproctol 2019;23:903-11.

56. Larsen S, Pfeffer F, Kørner H. Norwegian moratorium on transanal total mesorectal excision. Br J Surg 2019;106:1120-1.

57. Pontallier A, Denost Q, Van Geluwe B, Adam JP, Celerier B, et al. Potential sexual function improvement by using transanal mesorectal approach for laparoscopic low rectal cancer excision. Surg Endosc 2016;30:4924-33.

58. Kneist W, Wachter N, Paschold M, Kauff DW, Rink AD, et al. Midterm functional results of taTME with neuromapping for low rectal cancer. Tech Coloproctol 2016;20:41-9.

59. Koedam TW, van Ramshorst GH, Deijen CL, Elfrink AK, Meijerink WJ, et al. Transanal total mesorectal excision (TaTME) for rectal cancer: effects on patient-reported quality of life and functional outcome. Tech Coloproctol 2017;21:25-33.

60. Rubinkiewicz M, Zarzycki P, Witowski J, Pisarska M, Gajewska N, et al. Functional outcomes after resections for low rectal tumors: comparison of Transanal with laparoscopic Total Mesorectal excision. BMC Surg 2019;19:79. 
61. Leão P, Santos C, Goulart A, Caetano AC, Sousa M, et al. TaTME: analysis of the evacuatory outcomes and EUS anal sphincter. Minim Invasive Ther Allied Technol 2019;28:332-7.

62. Park EJ, Cho MS, Baek SJ, Hur H, Min BS, et al. Long-term oncologic outcomes of robotic low anterior resection for rectal cancer: a comparative study with laparoscopic surgery. Ann Surg 2015;261:129-37.

63. Kuo LJ, Ngu JC, Tong YS, Chen CC. Combined robotic transanal total mesorectal excision (R-taTME) and single-site plus one-port (R-SSPO) technique for ultra-low rectal surgery-initial experience with a new operation approach. Int J Colorectal Dis 2017;32:249-54.

64. Hu JM, Chu CH, Jiang JK, Lai YL, Huang IP, et al. Robotic transanal total mesorectal excision assisted by laparoscopic transabdominal approach: a preliminary twenty-case series report. Asian J Surg 2020;43:330-8.

65. Atallah S. Transanal total mesorectal excision: full steam ahead. Tech Coloproctol 2015;19:57-61.

66. Wexner SD, Berho M. Transanal TAMIS total mesorectal excision (TME) - a work in progress Tech Coloproctol 2014;18:423-5.

67. Wexner SD, Berho M. Transanal total mesorectal excision of rectal carcinoma: evidence to learn and adopt the technique. Ann Surg 2015;261:234-6.

68. Williams NS. The rectal "no man's land" and sphincter preservation during rectal excision. Br J Surg 2010;97:1749-51.

69. Seow-Choen F. Ultra-low anterior resection for low rectal cancer: five key tips to make it easy. Tech Coloproctol 2009;13:89-93.

70. Heald RJ. A new solution to some old problems: transanal TME. Tech Coloproctol 2013;17:257-8.

71. Francis N, Penna M, Carter F, Mortensen NJ, Hompes R, et al. Development and early outcomes of the national training initiative for transanal total mesorectal excision in the UK. Colorectal Dis 2020; Epub ahead of print. DOI: 10.1111/codi.15022. 